\title{
Personel Seçimi Sürecinin AHP Tabanlı MOORA Yöntemi ile Değerlendirilmesi: Liman Saha Operasyon Elemanı Seçimi Üzerine Bir Uygulama
}

DOI: $10.26466 /$ opus.716542

\author{
Aynur Acer* - Hacer İnci** \\ *Öğr. Üyesi Dr., İstanbul Arel Üniversitesi İ.İ.B.F., İstanbul/Türkiye \\ E-Posta: aynuracer@arel.edu.tr \\ ORCID: 0000-0002-7315-7020 \\ ${ }^{* *}$ Uzman, Trabzon/Türkiye \\ E-Posta: hacerinci82@gmail.com \\ ORCID: $\underline{0000-0001-6158-8344}$
}

\begin{abstract}
Öz
Bütün üretim girdilerini kullanma becerisine sahip olan insan, işletmenin faaliyet gösterdiği sektörde tutunabilmesi ve devamlılı̆̆ın sağlayabilmesi için organizasyon ve yönetim faaliyetlerini sırtlanan, daha da önemlisi işletmeye farkındalık yaratan ve yenilik getiren unsurların başında yer almaktadır. Günümüzde işletmeler, her geçen gün artan rekabet ortamında çalışan personele yatırımın göz ardı edilerek fiziksel kaynaklara tek başına yatırım yapmanın fayda sağlamayacă̆ını benimsemiş bulunmaktadır. Mevcut durum, işletmelerin bünyesindeki insan kaynakları birimine olan farkındalı̆̆ ön plana çıkarmış ve insan kaynaklarının işlevlerinden biri olan personel seçme ve yerleştirme sürecinin gelişmesine neden olmuştur. Personel seçme ve yerleştirme aşaması, insan kaynağından etkin bir şekilde yararlanma aşamasının başlangıcıdır. Bu nedenle, küreselleşmenin her geçen gün hız kazandığı ortamda işletmeler doğru işe uygun ve nitelikli bir eleman seçebilmek ve seçilen bu elemanların işletme bünyesinde devamlılı̆̆ını sağlayabilmek için yarış içerisindedir. Bu çalışmada insan kaynakları yönetiminin önemli işlevlerinden biri olan personel seçimi süreci ele alınmıştır. Uygulama aşamasında Türkiye'nin en önemli limanlarından biri olan Trabzon Limani'nda saha operasyon eleman seçimi süreci çok kriterli karar verme yöntemlerinden AHP ve MOORA yöntemleri ile değerlendirilmiştir. Elde edilen bulgular "başvuru sonrası ölçütler (mülakat, sınav sonuçları ve referanslar)" in personel seçim sürecinde en önemli etken olduğunu göstermektedir.
\end{abstract}

Anahtar Kelimeler: Personel Seçme ve Yerleştirme, MOORA, Analitik Hiyerarşi Süreci, Çok Kriterli Karar Verme 


\title{
The Evaluation of Personnel Selection Process with AHP Based MOORA Method: An Application on Selection of Port Field Operations Staff
}

\begin{abstract}
Humans, who have the ability to use all production inputs, are the primary resources supporting organizational and management activities, and more importantly, raising awareness and bringing innovation to the enterprise in order to keep it in the sector where it operates. Today, enterprises have figured that investing in physical resources alone will not bring the full potential benefit when not done in parallel to investment in staff operating in an increasingly competitive environment. Today's business environment has emphasized the awareness of the human resources unit within the enterprises and led to the development of the personnel selection and placement process, which is one of the functions of the human resources. The personnel selection and placement phase are the beginning of the effective utilization of human resources. Therefore, in an environment where globalization is gaining momentum every day, enterprises are in a race to choose a suitable and qualified employee for the right job and to ensure the continuity of these selected elements within the business. In this study, the problem of personnel selection, which is one of the important functions of human resources management, is discussed. In the evaluation phase, the personnel selection for field operations of Trabzon Port, one of Turkey's most important ports, is evaluated with the multi-criteria decision-making methods called AHP and MOORA. Findings indicated that "post-application criteria (interview, exam results and references)" are an important factor in the personnel selection process.
\end{abstract}

Keywords: Personnel Selection and Placement, MOORA, Analytical Hierarchy Process, Multiple Criteria Decision Making 


\section{Giriş}

İnsan kaynaklarının öneminin fark edilmesi beraberinde örgütlerde bu alanla ilgili insan kaynakları yönetimi (İKY) biriminin ayrı bir yönetim birimi olarak bulundurulmasını zorunlu kılmıştır. İnsan kaynağının etkin ve verimli çalışmasını esas alan bu birim örgütteki insan kaynakları faaliyetlerini gerçekleştirmektedir. Günümüzde insan kaynakları (IK) kavramı personel yönetiminin değişime uğrayan rolü ve niteliği için kullanılmakta; personel yönetimi anlayışının mevcut sorunların giderilmesinde eksik kalması, personel yönetiminin rolü ve niteliğinin değişmesini zorunlu kılmıştır (Kaynak vd., 2015).

İnsan kaynakları yönetimi kavramının organizasyon içindeki görev tanımı özetle "çalışanların motivasyonunu ve etkinliğini arttıracak bir ortamın sağlanması ve bu ortamın korunup, geliştirilebilmesi için gerekli politikaların ve teknik bilginin tedarik edilmesi" olarak ifade edilmektedir (Palmer ve Winters, 1993; Çev: Şahiner, 1993). İnsan kaynakları kavramının, ilk olarak 1817 yılında dünya çapında tanınmış olan ekonomist Springer tarafından kullanıldığı kabul görmektedir. Kavramın içerik bakımından bir bütünlüğe kavuşması ise; Taylor ve Fayol'un yönetim alanındaki fikirleri ile gelişmiştir (Torrington, 1989: Armstrong, 2004). Günümüzde bu birim ile organizasyon içerisindeki en önemli kaynağın "insan" olduğu düşüncesi, bir klişe olmaktan çıkmış ve şirket yönetimleri için stratejik anlamlar ifade etmeye başlamıştır. Yönetimler, artık bir örgütteki en önemli ağırlık noktasının insan olduğunun farkına varmıştır. Gerekli olan tüm teçhizat ve donanım sağlanmış olsa dahi insan faktörü göz ardı edildiği sürece hiçbir şey gerçekleştirilemeyecektir.

İşletmelerde işe alma faaliyeti yeni çalışan gereksinimin hissedilmesi sonucu ortaya çıkar; arzu edilen ise planlama dâhilinde öngörüye dayalı etken bir insan kaynakları politikasının oluşturulmasıdır. Aynı zamanda işin pozisyonuna göre eleman seçmek ana gayedir. Bunun gerçekleşmesi için de öncelikli iş analizlerinin, iş tanım ve gereklerinin biliniyor olması gerekmektedir. İnsan kaynakları yönetim uygulamalarında seçme ve yerleştirme aşaması öteki insan kaynakları fonksiyonlarını birebir etkileyen bir yapıdadır. Stratejik yapı ile uyum içerisinde olacak diğer insan kaynakları fonksiyonlarını destekleyecek tarzda çalışan seçimi yapılması esastır (Oral, 2018). 
İnsan kaynağını bulma aşaması, işletmede doğan personel ihtiyacını gidermek için gerekli bilgi, yetenek, beceri ve motivasyona haiz adaylara yönelik yapılan araştırma ve akabinde uygun görülen adayları işletmeye alabilme, işletmede uygun pozisyonlarda çalıştırabilme faaliyetleridir (Tortop vd., 2007 , s.126). Eleman seçme eyleminin temel amacı adayın sahip olduğu yetenekleri ile işin gerekleri arasındaki en uygun ilişkiyi kurabilmek için işletmeye müracaat etmiş adayların kişiliklerini, edinmiş oldukları eğitimleri, haiz oldukları becerileri ve ilgilendikleri alanları inceleyerek, adaylar içerisinde iş gören ve işletme için en nitelikli adayı işletme bünyesine katabilmektir. Özetle, nitelikli işlevselliğe sahip iyi bir insan kaynakları seçiminden aranan ve istenen; işletmenin menfaatleriyle adayların menfaatlerini uyumlu bir şekle dönüştürmektir (Buğdaycı,1997, s.168-169).

Personel seçiminde verilen yanlış kararlar ve akabinde liyakatsiz adayın işe alınması kurum için ciddi risk unsuru teşkil etmekle birlikte bu hatalı davranış kurumun para, zaman, iş, saygınlık ve müşteri kaybetmesine neden olabilmektedir. Kurumlarda ihtiyaç dâhilde oluşan açık pozisyonlar için insan kaynağını belirlerken üzerinde ciddi bir şekilde durması gereken olay iş için gereken standart ve niteliklerin seçilecek kişinin özellikleri ile uyumlu olmasidır (Ertürk, 2011, s. 89).

Personel seçme ve yerleştirmenin amacı adayın iş yapma yeteneğini değerlendirmektir. Bu amaç başarılı çalışanların ihtiyaç duyduğu temel özellikleri listeleyen iş analizleri ile yapılabilmektedir. Personel seçiminde aşağıda belirtilen kriterler önemlidir (Cook, 2009, s.10): Zihinsel yetenek, fiziksel özellikler, kişilik, ilgi alanları, değerler ve uyum, bilgi ve tecrübe, iş kabiliyeti, adayla ilgili toplanan bilgilerin niteliği, iş performansı. İş analizleri yardımı ile hangi işlere eleman temini yapılacağı ve bu işler için ihtiyaç duyulan niteliklerin ve özelliklerin belirlenmesi kararı verilmektedir. İş analizi akabinde boşalan veya yeni açlan bir işin tüm nitelik, incelik, ustalık ve çalışma şartları net bir şekilde ortaya sunulmuş olmaktadır (Benli ve Şahin, 2004, s.113-124). Personel alımı yapılırken üzerinde durulması gereken diğer bir konu ise işe alınacak olan kişinin kurum yapısına ve kültürüne uyumudur. Uyumun olduğu yerde verimlilik ve düzen vardır.

Bu çalışma insan kaynakları yönetiminin en önemli işlevlerden biri olan personel seçimi probleminin hangi kriterler ışı̆̆ında değerlendirildiğini ele almaktadır. Trabzon Limanı'nda saha operasyon elemanı olarak görev yapacak en uygun adayın seçilmesi süreci bilimsel yaklaşımlarla değerlendirmeye 
tabi tutulmuştur. Yöntem olarak literatürde de sıklıkla kullanılan çok kriterli karar verme (ÇKKV) yöntemlerinden faydalanılmıştır. AHP yöntemi ile adayların değerlendirilmesinde esas alınan ana ve alt kriterlerin göreceli önem dereceleri belirlenmiştir. Alternatifleri oluşturan saha operasyon elemanı seçiminde ise MOORA yöntemi kullanılmıştır.

\section{Literatür Taraması}

Personel seçimi probleminde ilk uygulama Taylor vd. (1998) tarafından bir fakülteye dekan atanmasında AHS yöntemi kullanılarak ele alınmıştır. Çalışmada kullanılan karar kriterleri; akreditasyon süreçleri ile bilgi ve deneyimi, idari görev deneyimi, yayınları ve fon bulma becerisidir. 33 farklı aday bu kriterler doğrultusunda değerlendirmeye tabi tutulmuştur.

Güngör vd. (2009) tarafından başlangiçta Bulanık AHS yöntemi ile personel seçimi problemi değerlendirilmiştir. Ana kriterler genel iş faktörleri, işe yönelik faktörler, tamamlayıcı iş faktörleri olmak üzere üç grupta değerlendirilmiştir ve 17 alt kriter çalışmada yer almaktadır. Elde edilen sonuçlar daha sonra Yager'in Hedef Ağırlıklandırma Yöntemi ile elde edilen sonuçlarla karşlaştırılarak değerlendirmeye tabi tutulmuştur.

Baležentis vd. (2012), Kelime ve Bulanık Hesaplamaya Dayalı Personel Seçimi çalışmasında MOORA yöntemi kullanılarak değerlendirme yapılmıştır. El-Santawy ve Ahmed (2013) tarafından personel eğitimi seçimi problemi SDV-MOORA yöntemleri kullanılarak değerlendirilmeye tabi tutulmuştur.

Tepe ve Görener (2014) çalışmasında iletişim sektöründe faaliyette bulunan bir şirketin ara kademe yönetici personel seçim sürecini ele almış ve personel seçiminde MOORA yöntemini uygulamıştır.

Özbek (2015) tarafından uygulanan modelde Analitik Hiyerarşi Süreci (AHS) ve Multi-Objective Optimization on the basis of Ratio Analysis (MOORA) yöntemleri bütünleşik olarak kullanılmıştır. Yönetici seçimi probleminin ölçüt ağırlıkları AHS ile belirlenmiş ve en uygun yöneticinin seçimi ise Multi-MOORA yöntemine göre yapılmıştır. Çalışma sonuçları MYO'lara yönetici seçiminde en önemli kriterin "sosyal ilişkiler" olduğunu ortaya koymuştur. Ayrıca bulgular MOORA yönteminin çeşitli sürümlerinde birbirine benzer sonuçlara ulaşıldığını göstermiştir.

Akar ve Çakır (2015), personel seçimini Bulanık AHP ve MOORA yöntemlerini kullanılarak değerlendirmiştir. 
Çelikbilek (2018) tarafından personel seçimi için bütünleşik gri AHP-MOORA yaklaşımı önerisinde bulunulmuştur. Gri sayıların tercih edilmesinin nedeni, kişisel yargıları temsil yeteneğindeki başarısı ve seçimler sırasında kişisel yargılardan kaynaklı yanlılıkların minimize edilerek işlemlere dahil edilmesidir.

Çok farklı alanlarda personel seçimi ile ilgili çalışmalar olmasına karşın uluslararası ticarette önemli bir paya sahip olan limanlarda operasyonel alanda personel seçimi problemi ile ilgili literatürde bir çalışma yer almamaktadır. Bu nedenle saha operasyon personeli seçimini konu alan bu çalışmanın literatüre katkı sağlayacağı düşünülmektedir.

\section{Yöntem}

Çok sayıda alternatif kümesinden en az bir amaç veya ölçüte göre en uygun seçeneğin seçimi karar verme problemini tanımlamaktadır. Dolayısıyla bir karar problemi; karar verici, kriterler veya ölçütler, alternatifler, sonuçlar ve öncelikler elemanlarının toplamından oluşmaktadır. Bir karar problemi en basit haliyle bir hedef, bu hedefi etkileyen kriterler ve alternatiflerden oluşmakta ve bu hedefi etkileyen kriterlerden yola çıkarak en uygun alternatifin seçilmesi esasına dayanmaktadır (Saaty, 1980). 1960'lı yıllarda karar problemlerin çözümüne yardımcı olacak birtakım araçların gerekli görülmesiyle gelişmeye başlayan ÇKKV yöntemleri alternatif ve kriter sayılarının fazla olduğu karar verme mekanizmasını kontrol altında tutmak ve mümkün olduğu kadar kolay ve hızlı sonuç alabilmek (Herişçakar, 1999) adına geliştirilen farklı yöntemlerden oluşmaktadır. Alternatiflerin sayısal analizini içeren herhangi bir karar verme tekniğini kullanmanın üç adımı vardır (Triantaphyllou, 2000, s.5-6):

- İlgili kriterleri ve alternatifleri belirleme

- Kriterlerin göreceli önemine ve alternatiflerin bu ölçütler üzerindeki etkilerine sayısal ölçümler ekleme.

- Her bir alternatifin sıralamasını belirlemek için sayısal değerleri işleme.

Karar verme yöntemlerinin ve çeşitlerinin sürekli olarak çoğalmasıyla, onların karşılaştırmalı değerlerinin anlaşılması çok önemli hale gelmiştir. Bu konuda kullanılan yöntemlerden her biri, karar vericilerin farklı alternatif ka- 
rarlar arasından seçim yapmalarına yardımcı olmak için farklı sayısal teknikler kullanmaktadır. Bu alternatiflerin belirli kriterler üzerindeki etkisine ve dolayısıyla karar vericilerin genel faydasına dayanarak bulgular elde edilir. Karar yöntemlerini karşılaştırmaya ve en iyisini seçmeye çalışırken meydana gelen zorluk, bir paradoksun ortaya çımasına neden olabilir. ÇKKV özellikle alternatifler arasında ölçülmezlik ve karşılaştırılamazlık durumlarının söz konusu olduğu karar problemlerinde ilave yaklaşımlar ile bu durumu ortadan kaldıran çözümleri sunarak karar vericiye yardımcı olmaktadır (Urfalıoğlu ve Genç, 2013, s.332)

Literatürde ana ölçütlere göre alternatiflerin değerlendirilmesi ile ilgili çok sayıda ÇKKV yöntemleri kullanılmaktadır. Bu çalışmada AHP yöntemi ile ölçütlerin göreceli önem değerleri belirlenmiş ve MOORA yöntemi ile adayların performansları sıralanmıştır. Bu yöntemler ve adımları alt başlıklarda ayrıntılı irdelenmiştir.

\section{Analitik Hiyerarşi Süreci}

AHS tekniği, 1977 yılında Thomas L. Saaty tarafından geliştirilen (Saaty, 1990; Saaty, 2002), grup veya bireylerin önceliklerinin dikkate alınarak tespit edilen nicel ve nitel değişkenlerin bir arada değerlendirildiği ve karmaşık bir problemin basit bir hiyerarşi oluşturularak yapılandırılması temeline dayanan (Paksoy ve Atak, 2003) çok kriterli karar verme yöntemlerinden birisidir. Yöntem ikili karşılaştırmalar matrisi yardımıyla kriterler, alt ölçütler ve alternatifler için karar vericinin en iyi seçeneği seçmesine olanak sağlamaktadır. Şekil 1.'de genel bir karar verme probleminin AHS'ye göre hiyerarşik yapısı verilmiştir. 


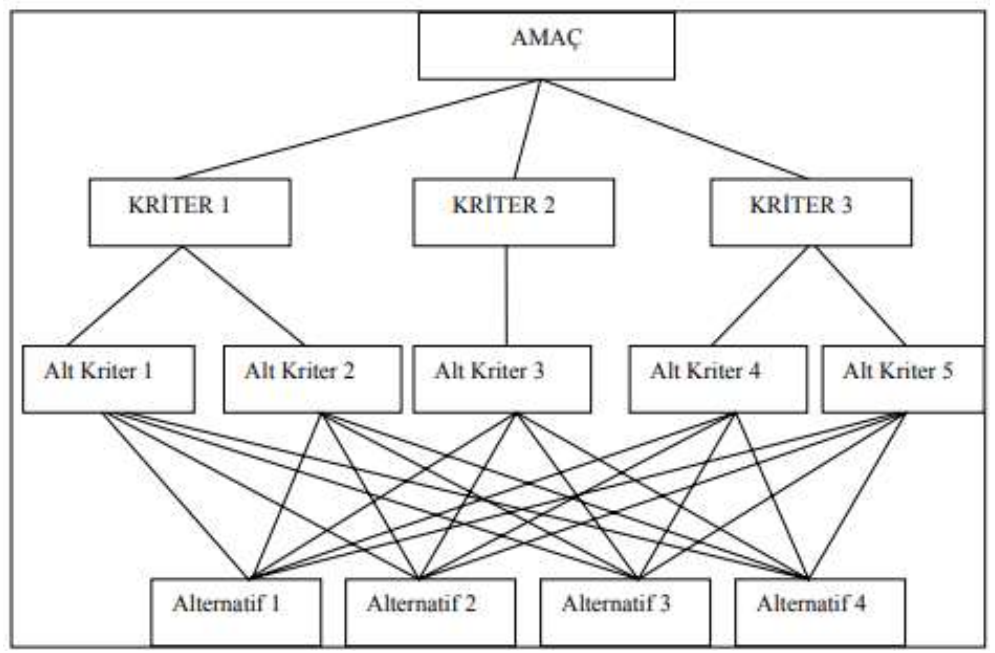

Şekil 1: AHP'nin Genel Hiyerarşik Yapısı (Alford, 2004, s.6)

Karar verme sürecini etkileyen tüm kriterlerin dikkate alınarak oluşturulduğu bu hiyerarşide tüm parçalar birbiri ile ilişkilidir ve duyarlılık analizleri ile bir kriterde meydana gelen değişimin diğerlerini nasıl etkilediği kolayca görülebilmektedir. Yöntemde kullanılan ikili karşılaştırma ölçeği aşağıda Tablo 1’de yer almaktadır.

Tablo 1. Karşılaştırmalarda kullanılan önem dereceleri tablosu

\begin{tabular}{ll}
\hline Önem Derecesi & Açıklama \\
\hline 1 & Karşılaştırılan iki ölçütte eşit derecede önemli \\
3 & Bir faktör diğerine göre biraz daha önemli \\
5 & Bir faktörün diğerine göre çok önemli olması \\
7 & Bir faktörün diğerine göre yüksek derece önemli olması \\
9 & Bir faktörün diğerine göre çok yüksek derecede önemli olması \\
\hline $2,4,6,8$ & Ara değerleri temsil etmektedir. \\
\hline
\end{tabular}

Kaynak: Saaty, 1982, s.78

Yapılan ikili karşılaştırmalar sonucunda kriterlerin önem derecelerini gösteren öncelik vektörü belirlenmektedir. Daha sonrasında ise tutarlılık oranı (CR) hesaplanmaktadır. Yapılan karşılaştırmaların tutarlı olması $C R \leq 10$ olmasına bağlıdır. Oranın 0,10'dan büyük olması halinde karşılaştırmaların tutarsız olduğu kabul edilir ve kadar vericiden yeniden değerlendirme yapması talep edilir. 
Son dönemlerde kantitatif verilere göre değerlendirme yapan bir yöntem olan ve ÇKKV yöntemleri arasında yer alan AHS yöntemi ile gerçek hayatta karşılaşılan karar verme problemlerine çözüm bulmak için yapılan çalışmalara literatürde sıkça rastlanmaktadır. AHS yöntemi farklı alanlarda uygulanabilen bir yöntem olup personel seçimi de bu uygulama alanlarından birisidir (Timor, 2011, s.151). Özellikle kriterlerin önem derecelerinin belirlenmesinde kullanılan AHS yöntemi bu çalışmada da kullanılmış ve Trabzon limanı'nda saha operasyon personel seçimi için kriter ağırlıkları Expert Choice paket programı ile elde edilmiştir. Adayları oluşturan alternatiflerin sıralanmasında ise MOORA yönteminden yararlanılmıştır.

\section{MOORA Yöntemi}

Brauers ve Zavadskas (2006) tarafından ilk defa uygulanan ve AHS, TOPSIS, ELECTRE, VIKOR gibi diğer çok kriterli karar verme yöntemlerine göre literatürde yeni olan ve yaygin kullanılan MOORA (Multu-Objective Optimization on the Basis of Ratio Analysis) yöntemi, oransal analize dayalı bir karar verme tekniği olarak karşımıza çıkmaktadır (Kalibatas ve Turskis, 2008; Yıldırım ve Önay, 2013; Tepe ve Görener, 2014, s.5). Yöntem, çok kriterli veya çok nitelikli karar verme olarak da bilinen çok amaçlı optimizasyon veya programlamada belirli kısıtlamalara tabi iki veya daha fazla çelişen hedefin aynı anda optimize edilmesi işlemi olarak ifade edilmektedir (Chakraborty, 2011, s.1156). MOORA yönteminde bir hedef üzerindeki bir alternatifin her cevabının, o hedefle ilgili tüm alternatifleri temsil eden bir payda ile karşılaştırıldığı oran sistemi kullanılmaktadır (Brauers ve Zavadskas, 2012). Çok amaçlı optimizasyon problemleri, ürün ve süreç tasarımı, finans, uçak tasarımı, petrol ve gaz endüstrisi, imalat sektörü, otomobil tasarımı gibi çeşitli sektörlerde uygulama alnı bulmaktadır.

İyileştirilmiş Nominal Grup ve Delphi tekniği ile desteklenen MOORA yönteminin oran sistemi, referans noktası yaklaşımı ve MOORA önem ağırlığı yaklaşımı olmak üzere üç türü bulunmaktadır.

\section{Oran yöntemi}

Aşağıda adımları belirtilen MOORA yöntemi (Brauers vd., 2006, 2009; Kalibatas vd., 2008; Lootsma, 1999; Gadakh, 2011, s.744) çeşitli hedeflere göre 
farklı alternatiflerin performansın gösteren bir karar matrisinin oluşturulması ile başlamaktadır.

- Adım 1: İlk olarak amaç tanımlanır ve ilgili değerlendirme ölçütleri belirlenir.

- Adım 2: Bu adımda eşitlik (1)'de yer alan alternatifleri ve alternatiflerin ilgili ölçütlere göre performans değerlerini içeren $X_{m x n}$ karar matrisi oluşturulmaktadır. Karar matrisi içinde yer alan her bir $x_{i j}$ değeri i. alternatifin $\mathrm{j}$. ölçüte göre performans değerlerini, $m=$ alternatif sayısını ve $n=0 ̈ l-$ çüt sayısını ifade etmektedir.

$$
X=\left[\begin{array}{cccc}
x_{11} & x_{12} & \ldots & x_{1 n} \\
x_{21} & x_{22} & \ldots & x_{2 n} \\
\vdots & \vdots & \vdots & \vdots \\
x_{m 1} & x_{m 2} & \ldots & x_{m n}
\end{array}\right\rfloor
$$

- Adım 3: Daha sonra her bir ölçüt üzerindeki bir alternatifin her performansının, o özellik ile ilgili tüm alternatifleri temsil eden payda ile karşılaştırıldığı bir oran sistemi geliştirilir. Bu oran aşağıdaki eşitlik (2)'de ifade edildiği gibi ölçüt başına her alternatifin kareleri toplamının karekökü ile elde edilmektedir.

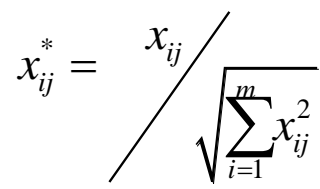

$$
(\mathrm{j}=1,2, \ldots, \mathrm{n})
$$

Buradaki $x_{i j}$, i. alternatifin j. ölçütte normalleştirilmiş performansını temsil eden $[0,1]$ aralığına ait boyutsuz bir sayıyı ifade etmektedir.

- Adım 4: Bu normalizasyon işleminin ardından hazırlanan tabloda ölçüt veya kriterler maksimum veya minimum olmalarına göre belirlenip toplanırlar. Çok amaçlı optimizasyon için bir önceki adımdaki bu normalleştirilmiş performans değerler maksimizasyon durumunda (faydalı özellikler için) eklenir ve minimizasyon (faydasız özellikler için) durumunda çıkarılır. 


$$
y_{i}=\sum_{j=1}^{g} x_{i j}^{*}-\sum_{j=g+1}^{n} x_{i j}^{*}
$$

Eşitlik (3)'de g=maksimize edilecek ölçüt sayı-

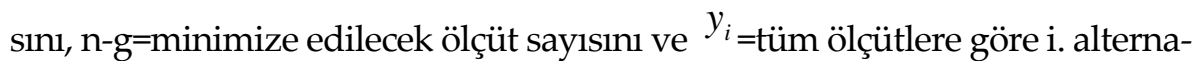
tifin normalleştirilmiş değerlendirme değerini ifade etmektedir.

\section{Referans noktası teorisi}

MOORA yönteminde normalleştirilmiş performans değerlerinin belirlenmesinden sonra oran metoduna ek olarak referans noktası teorisine göre maksimizasyon için tüm aday alternatiflerin her amaç için en yüksek koordinatı veren bir referans noktası ( ${ }_{j}=$ j. ölçütün referans noktası) ve minimizasyon için ise en düşük koordinat referans noktası olarak seçilir (Brauers ve Zavadskas, 2006, s.447). Bu noktaların her $x_{i j}^{*}$ 'den uzaklıkları eşitlik 4 ile

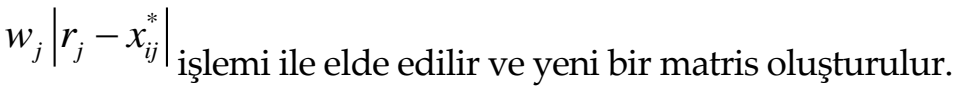

$$
r_{j}-x_{i j}^{*}
$$

Oluşturulan yeni matriste "Tchebycheff Min-Maks Metrik" işlemi eşitlik 5 yardımıla uygulanır ve sıralama yapılır (Önay, 2014, s. 248).

$$
\min _{i}\left\{\operatorname{maks}_{j}\left(\left|r_{j}-x_{i j}^{*}\right|\right)\right\}
$$

\section{MOORA önem katsayısı yaklaşımı}

Bu yöntemde oran yöntemi ile elde edilen normalleştirilmiş veriler temel alınmaktadır. Her amacın önceliklerinin farklı olduğu durumlarda alternatiflerin performans değerleri (Alnupak ve Yorulmaz, 2019, s.115) eşitlik 6 formülü ile hesaplanmaktadır.

$$
y_{i}^{*}=\sum_{j=1}^{g} w_{j} x_{i j}^{*}-\sum_{j=g+1}^{n} w_{j} x_{i j}^{*}
$$


Amaçların önem katsayılarının referans noktası yönteminde de kullanılması etkilidir. Bu durumda eşitlik 4 formülü önem katsayıları ile çarpılarak aşağıdaki eşitlik 7 elde edilir.

$$
w_{j}\left|r_{j}-x_{i j}^{*}\right|
$$

Literatürde MOORA yöntemi çoğunlukla oran metodu ve referans noktası yöntemi olmak üzere iki bölüm halinde hesaplanmaktadır. Yapılan uygulamaların bazılarında her iki yöntem birlikte kullanılırken bazı çalışmalarda ise yöntemlerden sadece biri seçilerek sıralama yapılmaktadır (Önay, 2014, s.246). Bu çalışmada adayların sıralanmasında, saha operasyon elemanları her iki yöntemle değerlendirmeye tabi tutulmuş ve aynı sıralama sonuçları elde edilmiştir. Bu nedenle çalışmanın uygulama aşamasında sadece referans noktası yaklaşımı ile elde edilen sonuçlara yer verilmiştir.

\section{Bulgular}

Özel veya kamu işletmelerinde gerçekleştirilen faaliyetlerin başarısı çoğunlukla çalıştırılan işgörenlerin niteliğine bağlıdır. Bu nedenle tüm alanlarda işgörenlerin değerlendirilmesi ve en uygun adayın seçimi hem firma için hem de aday için büyük önem taşımaktadır (Timor, 2011, s.151). Personel seçimi problemlerinde karar vericiler bireysel potansiyel değerlendirmeleri yoluyla adayın kişisel kariyer sonuçlarını doğrudan etkileyerek (Castilla ve Benard, 2010, s.543); ödüllerin, fırsatların ve görevlerin tahsisini önemli ölçüde belirlemektedir.

Personel seçimi sürecinin farklı bir alanda değerlendirildiği bu çalışmada, uygulama aşamasında öncelikle saha operasyon elemanı seçiminde en uygun adayın belirlenmesinde hangi kriterlerin karar vericiyi etkilediği ile ilgili bir literatür taraması yapılmış ve bu ölçütler bu konuda uzman olan yöneticilerle birlikte değerlendirmeye tabi tutulmuştur. Tüm belirlenen ölçütleri oluşturan bir değerlendirme formu tekrar yöneticilere gönderilerek cevaplamaları talep edilmiştir. Uygulamada kriterlerin göreceli önem değerleri AHS yöntemi kullanılarak Expert Choice programı ile elde edilmiş ve bir alt başlıkta belirtilmiştir. 
Tablo 2. Ana ve alt değerlendirme ölçütleri

\begin{tabular}{|c|c|c|c|}
\hline \multirow{6}{*}{$\begin{array}{l}\text { Kişisel } \\
\text { Özellikler }\end{array}$} & Analitik Düşünme & K1 & 1-5: çok düşük, düşük, orta, yüksek, çok yüksek \\
\hline & Fiziksel Görünüm & $\mathrm{K} 2$ & 1-5: çok düşük, düşük, orta, yüksek, çok yüksek \\
\hline & Sağlık Durumu & $\mathrm{K} 3$ & 1-5: çok kötü, kötü, orta, iyi, çok iyi \\
\hline & Aile ve Sosyal Durum & K4 & 1-5: çok kötü, kötü, orta, iyi, çok iyi \\
\hline & Adayın Yaşı & K5 & Yaş \\
\hline & $\begin{array}{l}\text { Kendine Güven ve Kendini } \\
\text { İfade Edebilme }\end{array}$ & K6 & 1-5: çok kötü, kötü, orta, iyi, çok iyi \\
\hline \multirow{3}{*}{ Anlama } & Sözlü Anlama & K7 & 1-5: çok kötü, kötü, orta, iyi, çok iyi \\
\hline & Yazılı Anlama & K8 & 1-5: çok kötü, kötü, orta, iyi, çok iyi \\
\hline & $\begin{array}{l}\text { Anlama ve Anlatma } \\
\text { Yeteneği }\end{array}$ & K9 & 1-5: çok düşük, düşüuk, orta, yüksek, çok yüksek \\
\hline \multirow{5}{*}{$\begin{array}{l}\text { Liderlik } \\
\text { ve Göreve } \\
\text { Özgü } \\
\text { Yeterlilik }\end{array}$} & Disiplin & K10 & 1-5: çok düşük, düşük, orta, yüksek, çok yüksek \\
\hline & Vizyon & K11 & 1-5: çok kötü, kötü, orta, iyi, çok iyi \\
\hline & İnisiyatif Alma & K12 & 1-5: çok düşük, düşük, orta, yüksek, çok yüksek \\
\hline & Görev Bilinci & K13 & 1-5: çok düşük, düşük, orta, yüksek, çok yüksek \\
\hline & İletişim ve Sosyal Uyum & K14 & 1-5: çok kötü, kötü, orta, iyi, çok iyi \\
\hline \multirow{5}{*}{$\begin{array}{l}\text { Psikolojik } \\
\text { Özellikler }\end{array}$} & Olgunluk Seviyesi & K15 & 1-5: çok düşük, düşük, orta, yüksek, çok yüksek \\
\hline & Gönüllülük & K16 & $\begin{array}{l}\text { 1-5: çok gönülsüz, gönülsüz, orta, gönüllü, çok } \\
\text { gönüllü }\end{array}$ \\
\hline & Motivasyon ve İstek & K17 & 1-5: çok düşük, düşük, orta, yüksek, çok yüksek \\
\hline & İçine Kapanık Olmama & K18 & 1-5: çok kötü, kötü, orta, iyi, çok iyi \\
\hline & Yaratıcilık & K19 & 1-5: çok düşük, düşük, orta, yüksek, çok yüksek \\
\hline \multirow{5}{*}{$\begin{array}{l}\text { Bilimsel } \\
\text { Yeterlilik } \\
\text { ve Eğitim }\end{array}$} & $\begin{array}{l}\text { Mesleki Yetkinlik ve } \\
\text { Deneyim }\end{array}$ & K20 & Yil bazinda \\
\hline & Eğitim Durumu & K21 & $\begin{array}{l}\text { 1-5: } 1=\text { lise ve altı, } 2=\text { lise, } 3=\text { önlisans, } 4=\text { lisans, } 5=\text { =yük- } \\
\text { seklisans }\end{array}$ \\
\hline & Mezun Olunan Bölüm & $\mathrm{K} 22$ & $\begin{array}{l}\text { 1-5: hiç uyumlu değil, uyumlu değil, orta, uyumlu, } \\
\text { çok uyumlu }\end{array}$ \\
\hline & Bilgisayar Bilgisi & K23 & 1-5: çok kötü, kötü, orta, iyi, çok iyi \\
\hline & Yabancı Dil & K24 & 1-5: çok kötü, kötü, orta, iyi, çok iyi \\
\hline \multirow{3}{*}{ Diğer } & Mülakat & K25 & Mülakat puanı \\
\hline & Referanslar & K26 & 1-5: çok kötü, kötü, orta, iyi, çok iyi \\
\hline & Değerlendirme Testi & K27 & değerlendirme puanı \\
\hline
\end{tabular}

Alternatiflerin siralanmasinda ise Tablo $2^{\prime}$ de verilen skala ile elde edilen cevaplar MOORA yöntemi adımları ile hesaplanmıştır.

\section{Kriter ă̆ırlıklarının belirlenmesi}

Kriterlerin belirlenmesinde ilk olarak personel seçimi ile ilgili literatürde yer alan çalışmalar irdelenmiştir. Elde edilen kriterler Trabzon Limanı'nda personel seçimi konusunda yetkin 5 yöneticiye gönderilmiş ve hangi kriterlerin saha operasyon elemanı seçiminde önemli hangilerinin önemsiz olduğunu 
belirlemeleri istenmiştir. Yönetici ve uzmanların tavsiyeleri üzerine gerekli ekleme ve çıkartmalar yapılarak personel seçimi sürecinde toplamda altı ana kriter belirlenmiştir: Kişisel özellikler, anlama, liderlik ve göreve özgü yeterlilik, psikolojik özellikler, bilimsel yeterlilik ve eğitim, diğer (Başvuru sonrası değerlendirme ölçütleri). Alt kriterlerle birlikte toplamda 27 ölçüt elde edilmiş ve değerlendirmeye tabi tutulmuştur. Kriter ağırlıklarının hesaplanması için bir anket formu düzenlenmiş ve bu değerlendirme formu beş uzmana yeniden gönderilerek cevaplandırmaları talep edilmiştir. Elde edilen sonuçların geometrik ortalamaları alınarak aşağıda belirtilen karşılaştırmalar matrisi oluşturulmuştur. Bu bilgiler Expert Choice (EC) paket programına girilerek ölçütlerin ağırlıkları veya önem düzeyleri belirlenmiştir.

Tablo 3. Ana kriterlere ilişkin karşılaştırma matrisi

\begin{tabular}{llllllll}
\hline & $\begin{array}{l}\text { Kişisel } \\
\text { Özel- } \\
\text { likler }\end{array}$ & $\begin{array}{l}\text { An- } \\
\text { lama }\end{array}$ & $\begin{array}{l}\text { Liderlik ve } \\
\text { Göreve Özgü } \\
\text { Yeterlilikler }\end{array}$ & $\begin{array}{l}\text { Psikolojik } \\
\text { Özellikler }\end{array}$ & $\begin{array}{l}\text { Bilimsel Yeterlilik } \\
\text { ve Eğitim }\end{array}$ & Diğer & $\begin{array}{l}\text { Önem } \\
\text { Düzeyi }\end{array}$ \\
\hline $\begin{array}{l}\text { Kişisel } \\
\text { Özellikler }\end{array}$ & 1,000 & 3,000 & 1,000 & 2,000 & 3,000 & 3,000 & 0,099 \\
\hline Anlama & 0,333 & 1,000 & 3,000 & 1,000 & 4,000 & 5,000 & 0,198 \\
\hline $\begin{array}{l}\text { Liderlik ve } \\
\text { Göreve Özgü } \\
\text { Yeterlilikler }\end{array}$ & 1,000 & 0,333 & 1,000 & 2,000 & 3,000 & 3,000 & 0,128 \\
\hline $\begin{array}{l}\text { Psikolojik } \\
\text { Özellikler }\end{array}$ & 0,500 & 1,000 & 0,500 & 1,000 & 2,000 & 3,000 & 0,125 \\
\hline $\begin{array}{l}\text { Bilimsel Yeter- } \\
\text { lilik }\end{array}$ & 0,333 & 0,250 & 0,333 & 0,500 & 1,000 & 3,000 & 0,057 \\
\hline $\begin{array}{l}\text { ve Eğitim } \\
\text { Diğgr }\end{array}$ & 0,333 & 0,200 & 0,333 & 0,333 & 0,333 & 1,000 & 0,394 \\
\hline Sütun Toplamı & 3,500 & 5,783 & 6,167 & 6,833 & 13,333 & 18,000 & 1 \\
\hline
\end{tabular}

Saha operasyon elemanı seçiminde en önemli ana kriter 0,39 ile başvuru sonrası diğer ölçütler olarak karşımıza çıkmaktadır. Bu sıralamayı liderlik ve göreve özgü yetenekler, psikolojik özellikler, anlama, kişisel özellikler ve bilimsel yeterlilik ve eğitim takip etmektedir. Ana ölçütler için tutarlılık oranı ise 0,10'dan küçük olarak hesaplanmıştır. Ana kriterlerin değerlendirilmesinden sonra alt kriterler kendi içinde karşılaştırmalar matrisi oluşturularak değerlendirilmeye tabi tutulmuştur. 
Tablo 4. Kişisel özellikler alt kriteri için oluşturulan karşılaştırma matrisi

\begin{tabular}{llllllll}
\hline & K1 & K2 & K3 & K4 & K5 & K6 & Önem Düzeyi \\
\hline K1 & 1,000 & 3,000 & 8,000 & 4,000 & 7,000 & 6,000 & 0,028 \\
K2 & 0,333 & 1,000 & 5,000 & 3,000 & 6,000 & 4,000 & 0,052 \\
K3 & 1,000 & 0,200 & 1,000 & 7,000 & 4,000 & 3,000 & 0,441 \\
K4 & 0,250 & 0,333 & 0,143 & 1,000 & 1,000 & 4,000 & 0,096 \\
K5 & 0,143 & 0,167 & 0,250 & 1,000 & 1,000 & 3,000 & 0,143 \\
K6 & 0,167 & 0,250 & 0,333 & 0,250 & 0,333 & 1,000 & 0,240 \\
\hline Sütun Toplam1 & 2,893 & 4,950 & 14,726 & 16,250 & 19,333 & 21,000 & 1 \\
\hline Tutarlllk Oran1 & & & & & 0,09 \\
\hline
\end{tabular}

Tablo 4'te "Kişisel özellikler" alt ölçütünün ikili karşılaştırma sonuçları yer almaktadır. Sağlık durumu $(0,44)$ ve kendine güven ve kendini ifade edebilme $(0,24)$ alt kriteri, kişisel özellikler ana kriterli içinde en önemli ölçütlerdir.

Tablo 5. Anlama alt kriteri için oluşturulan karşılaştırma matrisi

\begin{tabular}{lllll}
\hline & K7 & K8 & K9 & Önem Düzeyi \\
\hline K7 & 1,00000 & 7,00000 & 2,00000 & 0,592 \\
K8 & 0,14286 & 1,00000 & 5,00000 & 0,075 \\
K9 & 0,50000 & 0,20000 & 1,00000 & 0,333 \\
\hline Sütun Toplamı & 1,64286 & 8,20000 & 8,00000 & 1,00 \\
\hline Tutarlllı Oranı & & & 0,01 \\
\hline
\end{tabular}

Tablo 5'de "Anlama" alt ölçütünün ikili karşılaştırma matrisi yer almaktadır. Sözlü anlama $(0,59)$ ve anlama ve anlatma yeteneği $(0,33)$ alt kriteri en önemli ölçüt olarak değerlendirilmiştir.

Tablo 6. Liderlik ve göreve özgü yeterlilik alt kriteri için oluşturulan karşılaştırma matrisi

\begin{tabular}{|c|c|c|c|c|c|c|}
\hline & K10 & K11 & K12 & K13 & K14 & Önem Düzeyi \\
\hline K10 & 1,00000 & 6,00000 & 3,00000 & 1,00000 & 2,00000 & 0,327 \\
\hline K11 & 0,16667 & 1,00000 & 1,00000 & 4,00000 & 3,00000 & 0,068 \\
\hline K12 & 0,33333 & 1,00000 & 1,00000 & 5,00000 & 2,00000 & 0,081 \\
\hline K13 & 1,00000 & 0,25000 & 0,20000 & 1,00000 & 3,00000 & 0,364 \\
\hline K14 & 0,50000 & 0,33333 & 0,50000 & 0,33333 & 1,00000 & 0,160 \\
\hline Sütun Toplamı & 3,00000 & 8,58333 & 5,70000 & 11,3333 & 11,0000 & 1,00 \\
\hline Tutarlılık Oranı & & & & & & 0,02 \\
\hline
\end{tabular}

Yukarıdaki Tablo 6'da "Liderlik ve göreve özgü yeterlilik" alt ölçütünün ikili karşılaştırma matrisi yer almaktadır. Görev bilinci $(0,36)$, disiplin $(0,33)$ ve iletişim ve sosyal uyum $(0,16)$ alt kriterleri en önemli üç ölçüt olarak değerlendirilmiştir. 
Tablo 7. Psikolojik özellikler alt kriteri için oluşturulan karşılaştırma matrisi

\begin{tabular}{lllllll}
\hline & K15 & K16 & K17 & K18 & K19 & Önem Düzeyi \\
\hline K15 & 1,00000 & 2,00000 & 2,00000 & 1,00000 & 2,00000 & 0,127 \\
K16 & 0,50000 & 1,00000 & 1,00000 & 1,00000 & 1,00000 & 0,221 \\
K17 & 0,50000 & 1,00000 & 1,00000 & 2,00000 & 2,00000 & 0,292 \\
K18 & 1,00000 & 1,00000 & 0,50000 & 1,00000 & 1,00000 & 0,168 \\
K19 & 0,50000 & 1,00000 & 0,50000 & 1,00000 & 1,00000 & 0,193 \\
\hline Sütun Toplamı & 3,50000 & 6,00000 & 5,00000 & 6,00000 & 7,00000 & 1,00 \\
\hline \multicolumn{2}{l}{ Tutarlllık Oranı } & & & & & 0,02 \\
\hline
\end{tabular}

Yukarıdaki Tablo 7'de "Psikolojik özellikler" alt ölçütünün ikili karşılaştırma matrisi yer almaktadır. Motivasyon ve istek $(0,29)$, gönüllülük $(0,22)$ ve yaratıcllık $(0,19)$ alt kriterleri en önemli üç ölçüt olarak değerlendirilmiştir.

Tablo 8. Bilimsel yeterlilik ve eğitim alt kriteri için oluşturulan karşılaştırma matrisi

\begin{tabular}{lllllll}
\hline & K20 & K21 & K22 & K23 & K24 & Önem Düzeyi \\
\hline K20 & 1,0000 & 3,0000 & 6,0000 & 6,0000 & 7,0000 & 0,5140 \\
K21 & 0,3333 & 1,0000 & 4,0000 & 5,0000 & 5,0000 & 0,2720 \\
K22 & 0,1667 & 0,2500 & 1,0000 & 2,0000 & 3,0000 & 0,1030 \\
K23 & 0,1667 & 0,2000 & 0,5000 & 1,0000 & 1,0000 & 0,0580 \\
K24 & 0,1429 & 0,2000 & 0,3333 & 1,0000 & 1,0000 & 0,0530 \\
\hline Sütun Toplam1 & 1,8095 & 4,6500 & 11,8333 & 15,0000 & 17,0000 & 1,0000 \\
\hline Tutarlilik Oran1 & & & & & 0,04 \\
\hline
\end{tabular}

Tablo $8^{\prime}$ de "Bilimsel yeterlilik ve eğitim" alt ölçütünün ikili karşılaştırma matrisi yer almaktadır. Mesleki yetkinlik ve deneyim $(0,51)$, eğitim $(0,27)$ ve mezun olunan bölüm $(0,10)$ alt kriterleri en önemli üç ölçüt olarak değerlendirilmiştir.

Tablo 9. Diğer alt kriteri için oluşturulan karşılaştırma matrisi

\begin{tabular}{lllll}
\hline & K25 & K26 & K27 & Önem Düzeyi \\
\hline K25 & 1,00000 & 3,00000 & 1,00000 & 0,210 \\
K26 & 0,33333 & 1,00000 & 2,00000 & 0,550 \\
K27 & 1,00000 & 0,50000 & 1,00000 & 0,240 \\
\hline Sütun Toplamı & 2,33333 & 4,50000 & 4,00000 & 1,00 \\
\hline Tutarlllik Oranı & & & 0,02 \\
\hline
\end{tabular}

Yukarıda Tablo 9'da "Diğer" alt ölçütünün ikili karşılaştırma matrisi yer almaktadır. Sırasıyla referanslar $(0,55)$, değerlendirme testi $(0,24)$ ve mülakat $(0,21)$ en önemli üç alt ölçüt olarak değerlendirilmiştir. Saha operasyon elemanı seçiminde kullanılan alt ölçütler ve genel önem düzeyleri Tablo 10'da verilmiştir. 
Tablo 10. Değerlendirme kriterlerine ait genel önem düzeyi tablosu

\begin{tabular}{|c|c|c|c|}
\hline \multirow[t]{2}{*}{ Ana Kriterler } & \multirow{2}{*}{$\begin{array}{l}\text { Değerlendirme Alt Kriterleri } \\
\text { Analitik Düşünme }\end{array}$} & \multicolumn{2}{|c|}{ Genel Önem Düzeyi } \\
\hline & & K1 & 0,00277 \\
\hline \multirow{5}{*}{ Kişisel Özellikler } & Fiziksel Görünüm & $\mathrm{K} 2$ & 0,00515 \\
\hline & Sağllk Durumu & K3 & 0,04366 \\
\hline & Aile ve Sosyal Durum & K4 & 0,0095 \\
\hline & Adayın Yaşı & K5 & 0,01416 \\
\hline & Kendine Güven ve Kendini İfade Edebilme & K6 & 0,02376 \\
\hline \multirow{3}{*}{ Anlama } & Sözlü Anlama & K7 & 0,11722 \\
\hline & Yazılı Anlama & K8 & 0,01485 \\
\hline & Anlama ve Anlatma Yeteneği & K9 & 0,06593 \\
\hline \multirow{5}{*}{$\begin{array}{l}\text { Liderlik ve } \\
\text { Göreve Özgü Yeterlilik }\end{array}$} & Disiplin & K10 & 0,04186 \\
\hline & Vizyon & K11 & 0,0087 \\
\hline & İnisiyatif Alma & K12 & 0,01037 \\
\hline & Görev Bilinci & K13 & 0,04659 \\
\hline & İletişim ve Sosyal Uyum & K14 & 0,02048 \\
\hline \multirow{5}{*}{ Psikolojik Özellikler } & Olgunluk Seviyesi & K15 & 0,01588 \\
\hline & Gönüllülük & K16 & 0,02763 \\
\hline & Motivasyon ve İstek & K17 & 0,0365 \\
\hline & İçine Kapanık Olmama & K18 & 0,021 \\
\hline & Yaraticllk & K19 & 0,02413 \\
\hline \multirow{5}{*}{$\begin{array}{l}\text { Bilimsel Yeterlilik } \\
\text { ve Eğitim }\end{array}$} & Mesleki Yetkinlik ve Deneyim & K20 & 0,0293 \\
\hline & Eğitim Durumu & K21 & 0,0155 \\
\hline & Mezun Olunan Bölüm & K22 & 0,00587 \\
\hline & Bilgisayar Bilgisi & K23 & 0,00331 \\
\hline & Yabanci Dil & K24 & 0,00302 \\
\hline \multirow{3}{*}{ Diğer } & Mülakat & K25 & 0,08274 \\
\hline & Referanslar & K26 & 0,2167 \\
\hline & Değerlendirme Testi & K27 & 0,09456 \\
\hline
\end{tabular}

\section{Alternatiflerin siralanması}

Alternatiflerin değerlendirilmesi ile ilgili belirlenen anket formu, personel seçimi konusunda söz sahibi ve direk karar verici durumunda olan üç yöneticiye gönderilmiştir. Alternatiflerin kriterlere göre değerlendirilmesinde 5'li ölçütler kullanılmış ve Tablo 2'de açıklamaları verilmiştir. Adayın yaşı ile ilgili belirlenen ifade edilen ölçütte direk adayın yaş bilgileri dikkate alınmış ve minimize edilmesi gereken bir kriter olarak belirlenmiştir. Bir diğer kriter olan mesleki yetkinlik ve deneyim ise adaylar için yıl bazında talep edilmiştir. Mülakat kriteri her aday için 10 puan üzerinden değerlendirilmeye tabi tutulmuş ve en büyüklenmesi istenmiştir. Bir diğer kriter olan değerlendirme testi ise her aday için 100 puan üzerinden değerlendirilmiş ve maksimize 
edilmek istenmiştir. Bu anket formları sonucunda elde edilen verilerin geometrik ortalaması alınıp MOORA yöntemi adımları kullanılarak üç aday s1ralamaya tabi tutulmuştur. Alternatiflerin ve alt ölçütlerin yer aldığı karar matrisi aşağıda Tablo 11'de verilmektedir.

Tablo 11. Karar matrisi

\begin{tabular}{llllllllll}
\hline Alternatifler & K1 & K2 & K3 & K4 & K5 & K6 & K7 & K8 & K9 \\
\hline A1 & 3 & 3 & 4 & 4 & 25 & 3 & 3 & 4 & 3 \\
A2 & 3 & 3 & 3 & 3 & 29 & 3 & 2 & 3 & 3 \\
A3 & 4 & 4 & 5 & 5 & 30 & 4 & 5 & 5 & 4 \\
\hline Toplam & 10 & 10 & 12 & 12 & 84 & 10 & 10 & 12 & 10 \\
\hline Alternatifler & K10 & K11 & K12 & K13 & K14 & K15 & K16 & K17 & K18 \\
\hline A1 & 3 & 3 & 3 & 3 & 4 & 3 & 4 & 3 & 2 \\
A2 & 3 & 2 & 3 & 2 & 3 & 3 & 3 & 3 & 2 \\
A3 & 5 & 4 & 4 & 4 & 5 & 5 & 5 & 5 & 2 \\
\hline Toplam & 11 & 9 & 10 & 9 & 12 & 11 & 12 & 11 & 6 \\
\hline Alternatifler & K19 & K20 & K21 & K22 & K23 & K24 & K25 & K26 & K27 \\
\hline A1 & 3 & 2 & 4 & 3 & 5 & 2 & 6 & 5 & 75 \\
A2 & 3 & 5 & 3 & 2 & 3 & 1 & 8 & 3 & 70 \\
A3 & 4 & 5 & 4 & 2 & 4 & 2 & 8 & 4 & 90 \\
\hline Toplam & 10 & 12 & 11 & 7 & 12 & 5 & 22 & 12 & 235 \\
\hline
\end{tabular}

Eşitlik-2 yardımı ile karar matrisi elemanları normalizasyon işlemine tabi tutulmuş ve Tablo 11'de belirtildiği gibi normalize edilmiş karar matrisi elde edilmiştir.

Tablo 12. Normalizasyon sonucu elde edilmiş karar matrisi

\begin{tabular}{|c|c|c|c|c|c|c|c|c|c|}
\hline Önem Düzeyi & 0,0028 & 0,0051 & 0,0437 & 0,0095 & 0,0142 & 0,0238 & 0,1172 & 0,0149 & 0,0028 \\
\hline Alternatifler & K1 & $\mathrm{K} 2$ & K3 & K4 & K5 & K6 & K7 & K8 & K9 \\
\hline A1 & 0,5145 & 0,5145 & 0,5657 & 0,5657 & 0,514 & 0,5145 & 0,4867 & 0,5657 & 0,5145 \\
\hline A2 & 0,5145 & 0,5145 & 0,4243 & 0,4243 & 0,5962 & 0,5145 & 0,3244 & 0,4243 & 0,5145 \\
\hline A3 & 0,686 & 0,686 & 0,7071 & 0,7071 & 0,6168 & 0,686 & 0,8111 & 0,7071 & 0,686 \\
\hline Önem Düzeyi & 0,0659 & 0,0419 & 0,0087 & 0,0104 & 0,0466 & 0,0205 & 0,0159 & 0,0276 & 0,0365 \\
\hline Alternatifler & K10 & K11 & K12 & K13 & K14 & K15 & K16 & K17 & K18 \\
\hline A1 & 0,4575 & 0,5571 & 0,5145 & 0,5571 & 0,5657 & 0,4575 & 0,5657 & 0,4575 & 0,5774 \\
\hline A2 & 0,4575 & 0,3714 & 0,5145 & 0,3714 & 0,4243 & 0,4575 & 0,4243 & 0,4575 & 0,5774 \\
\hline A3 & 0,7625 & 0,7428 & 0,686 & 0,7428 & 0,7071 & 0,7625 & 0,7071 & 0,7625 & 0,5774 \\
\hline Önem Düzeyi & 0,0241 & 0,0293 & 0,0155 & 0,0059 & 0,0033 & 0,003 & 0,0827 & 0,2167 & 0,0946 \\
\hline Alternatifler & K19 & K20 & K21 & $\mathrm{K} 22$ & $\mathrm{~K} 23$ & K24 & K25 & K26 & K27 \\
\hline A1 & 0,5145 & 0,2722 & 0,6247 & 0,7276 & 0,7071 & 0,6667 & 0,4685 & 0,7071 & 0,5496 \\
\hline A2 & 0,5145 & 0,6804 & 0,4685 & 0,4851 & 0,4243 & 0,3333 & 0,6247 & 0,4243 & 0,5129 \\
\hline A3 & 0,686 & 0,6804 & 0,6247 & 0,4851 & 0,5657 & 0,6667 & 0,6247 & 0,5657 & 0,6595 \\
\hline
\end{tabular}


Normalizasyon sonucu elde edilmiş karar matrisi referans noktası yaklaşımı eşitlik 3, 4 ve 5' de verilen formüller yardımı ile analize tabi tutulmuş ve Tablo 13' de verilen sonuçlar elde edilmiştir.

Tablo 13. Referans noktası yaklaşımında ağırlıkl normalize edilmiş değerler ve referans noktalar

\begin{tabular}{llllllllll}
\hline Referans Noktas1 & 0,0019 & 0,0035 & 0,0309 & 0,0067 & 0,0073 & 0,0163 & 0,0951 & 0,0105 & 0,0019 \\
\hline Alternatifler & K1 & K2 & K3 & K4 & K5 & K6 & K7 & K8 & K9 \\
\hline A1 & 0,0005 & 0,0009 & 0,0062 & 0,0013 & 0 & 0,0041 & 0,038 & 0,0021 & 0,0005 \\
A2 & 0,0005 & 0,0009 & 0,0124 & 0,0027 & 0,0012 & 0,0041 & 0,057 & 0,0042 & 0,0005 \\
A3 & 0 & 0 & 0 & 0 & 0,0015 & 0 & 0 & 0 & 0 \\
\hline Referans Noktas1 & 0,0452 & 0,0319 & 0,0065 & 0,0071 & 0,0346 & 0,0145 & 0,0121 & 0,0195 & 0,0278 \\
\hline Alternatifler & $\mathbf{K 1 0}$ & $\mathbf{K 1 1}$ & $\mathbf{K 1 2}$ & $\mathbf{K 1 3}$ & $\mathbf{K 1 4}$ & $\mathbf{K 1 5}$ & $\mathbf{K 1 6}$ & $\mathbf{K 1 7}$ & K18 \\
\hline A1 & 0,0113 & 0,0128 & 0,0016 & 0,0018 & 0,0087 & 0,0029 & 0,0048 & 0,0039 & 0,0111 \\
A2 & 0,0113 & 0,0128 & 0,0032 & 0,0018 & 0,0173 & 0,0058 & 0,0048 & 0,0078 & 0,0111 \\
\hline A3 & 0 & 0 & 0 & 0 & 0 & 0 & 0 & 0 & 0 \\
\hline Referans Noktas1 & 0,0166 & 0,0199 & 0,0097 & 0,0043 & 0,0023 & 0,002 & 0,0517 & 0,1532 & 0,0624 \\
\hline Alternatifler & $\mathbf{K 1 9}$ & $\mathbf{K 2 0}$ & $\mathbf{K 2 1}$ & $\mathbf{K 2 2}$ & $\mathbf{K 2 3}$ & $\mathbf{K 2 4}$ & $\mathbf{K 2 5}$ & $\mathbf{K 2 6}$ & $\mathbf{K} 27$ \\
\hline A1 & 0,0041 & 0,012 & 0 & 0 & 0 & 0 & 0,0129 & 0 & 0,0104 \\
A2 & 0,0041 & 0 & 0,0024 & 0,0014 & 0,0009 & 0,001 & 0 & 0,0613 & 0,0139 \\
A3 & 0 & 0 & 0 & 0,0014 & 0,0005 & 0 & 0 & 0,0307 & 0 \\
\hline
\end{tabular}

Referans noktası yöntemi sonucunda adayların her bir amaca göre referans noktasına olan uzaklıkları hesaplanmış ve adaylar Tablo 14'de sıralanmiştır.

Tablo 14. Referans noktası yaklaşımına göre alternatiflerin sıralanması

\begin{tabular}{lcc}
\hline Alternatifler & & Siralama \\
\hline A1 & 0,03803 & 2 \\
A2 & 0,06129 & 3 \\
A3 & 0,03065 & 1 \\
\hline
\end{tabular}

Son olarak her bir aday için elde edilen değerler küçükten büyüğe doğru sıralanarak referans noktasına en yakın aday en uygun aday olarak seçilir. Tablo 14'e göre saha operasyon elemanı seçimi için en uygun aday A3'tür.

\section{Sonuç}

İşletmelerin hedeflerine ulaşabilmek ve rakiplerine göre üstünlük oluşturmak için bunu gerçekleştirecek olan insanları bulmak, doğru bir seçim sürecinden geçirerek işe almak, motive etmek, verimli çalıştırmak, onları işletme 
içinde tutmak, adil biçimde performanslarını değerlendirmek ve kariyer yapabilme olanaklarına kavuşturmak zorundadır. Rekabet avantajının yaratılmasında insan kaynakları oldukça stratejik bir öneme sahiptir. Bu yapılanmayı sağlamanın başlangıç ve kilit aşamasını, göreve uygun olan personeli seçme süreci oluşturmaktadır. İşe ve işletmeye uygun elemanın bulunması ve istihdamı, gelecekte ortaya çıkabilecek birçok sorunun üstesinden gelinmesine, hizmet kalitesinin oluşturulmasına ve devamına önemli destek sağlayacaktır. Bu bakımdan işletmelerin işin niteliklerine ve koşullarına uygun, yenilikçi, yaratıcı ve gelişmeye açık elemanların seçimi ve istihdamı için yoğun çaba harcamaları gerekmektedir. İşletmeler sahip oldukları insan kaynaklarının niteliğini, doğru insanları seçerek artırabilir, aynı zamanda bu yolla işletme faaliyetlerini ve sonuçlarını iyileştirerek, performans ve kârlılıklarını artırabilirler. Bu bağlamda, bu süreçte meydana gelebilecek herhangi bir yanlışlı̆̆ın ileride işletme/organizasyon gelişimine ve verimliliğine olumsuz yönde yansıyacağı bilinmektedir.

Bu çalışmada daha önce literatürde uygulama alanı bulmayan liman saha personeli seçimi problemi çok kriterli karar verme yöntemlerinden AHS ve MOORA yöntemi ile değerlendirilmeye tabi tutulmuştur. Çalışmada altı ana kriter ve 27 alt kriter adayların değerlendirmesinde ölçüt olarak ele alınmış ve kriterlerin göreceli önem değerleri AHS yöntemiyle değerlendirilmiştir. Ana kriterler içinde en önemli ölçüt $(0,39)$ ağırlığı ile başvuru sonrası diğer kriterleri oluşturmaktadır. Bu kriter içinde ise personel seçimini etkileyen en önemli alt kriter "referans" olarak belirlenmiştir.

Son aşamaya kalan üç adayın değerlendirmesinde ise ağırlıkları belirlenen bu 27 alt kritere göre üç aday seçimi MOORA referans noktası teorisi ile değerlendirmeye tabi tutulmuştur. Değerlendirme sonucunda aday seçiminde öncelikle A3 adayının öncelikli işe alınması gereken aday olduğu belirlenmiştir. Bu sıralamayı A1 ve A2 takip etmektedir. İleride yapılacak çalışmalar için diğer çok kriterli karar verme yöntemleri kullanılarak personel seçimi konusu farklı alanlarda uygulanabilir. 


\title{
EXTENDED ABSTRACT
}

\section{The Evaluation of Personnel Selection Process with AHP Based MOORA Method: An Application on Selection of Port Field Operations Staff}

\author{
Aynur Acer - Hacer İnci \\ İstanbul Arel University
}

As the significance of the human resources is noticed, in the organizations, the human resources management department has become necessarily to exist as a separate unit. This department which grounds on the effective and production operation of the human resource accomplishes the human resources activities in the organization today, the concept of human resources is used for the role and feature of the personnel management which is changing in due course. The inadequacy of the personal management concept for the recovery of current problems necessitated the role and property of the personnel management to change (Source vd., 2015). Today, the though revealing that the most important resource in this unit is the "human" within the organization has become out of a cliché and begun to make strategic meanings for the managements of the company. Managements yet noticed that the most important and major point in an organization is the human. Despite all necessary equipment and instruments are provided, nothing can be achieved as long as the human factor is disregarded.

In the enterprises, recruitment activity arises as a result of the sensation of the necessity of new employee, what is desired here is to create an effective human resources policy based on foresight within the scope of planning. At the same time, it is the main purpose to select personnel in compliance with the position of the work for accomplishing it, prioritized work analyzes, work definition and requirements are required to be aware of. In human resources management applications, selection and placement stage is a kind of structure which affects other human resources functions one to one. It is basic that a selection should be made in such a manner to support other human resources functions which will be in harmony with the strategic structure (Oral, 2018). The stage of finding the human resource is the action; to commission and to 
employ in appropriate positions the applicants which are found competent as a result of the research made for the candidates having necessary knowledge, ability, skill and motivation for the purpose of recovering of personnel necessity in the organization (Tortop vd., 2007, s.126). The basic purpose of the selection of staff is to examine the personality, education and skills of the applicants, and the areas which they are interested in, in order to establish the best appropriate relation between the candidate's abilities and the requirements of the work, and to enable the most competent candidate in terms of desired qualifications to participate into the enterprise. In brief, what is searched and desired for a good selection of human resources with qualified functionality is that; to convert the enterprise's benefits and applicants' benefits into a coherent form. (Buğdaycı, 1997, s.168-169).

Wrong decisions made for the personnel selection and recruitment of a disqualified candidate subsequently entails a serious risk factor for the corporation, moreover this inaccurate selection may lead the organization to lose money, time, respect and customer. The purpose of personnel selection and placement is to assess the candidate's operational capacity. This objective can be achieved by work analyzes which list the basic properties which a successful employee requires. Criteria specified below are important for personnel selection process (Cook, 2009, s.10): Mental ability, physical properties, personality, fields of interest, values and coherence, knowledge and experience, work capability, the feature of the information collected for the candidate, work performance. Based on work analyzes, necessary decision may be given for the selection of staff for appropriate position and for the determination of necessary qualifications for this position. By the application of work analysis, all qualification, mastership and work conditions relevant with a work position which is becomes vacant or which has been already opened shall have been introduced apparently (Benli and Şahin, 2004, s.113-124). Another important point which is required to be dwelled on for the recruitment of personnel is the applicant's coherence and compliance the corporation's structure and culture. Productivity and order exist where the harmonization is available.

In this study, the problem of personnel election for the port site personnel which has not been applied in the literature previously is hereby assessed by AHS and MOORA procedure which is among multi- criteria-decision-making procedures. In the study, six main criteria and 27 sub criteria are used as criterion for the assessment of the candidates and the relative importance values of 
the criteria are evaluated by AHS procedure. The most important criterion among the main criteria hereby forms the other criteria after application with a weight of $(0,39)$. The most important sub criteria which affects the personnel selection among these criteria is hereby determined as;" reference".

As regards the assessment of the last three successful candidates; according to these 27 sub criteria of which relevant weights are determined, the selection of three candidates is assessed by MOORA reference point theory. As a result of the assessment, it is hereby determined that; for the selection of the personnel, A3 candidate should be recruited first, which is followed by A1 and A2. For the studies to be conducted in the future, other multi-decision-making procedures may be used and applied for personnel selection.

\section{Kaynakça / References}

Akar, G. S. ve Çakır, E. (2016). Lojistik sektöründe bütünleştirilmiş bulanık AHP-MOORA yaklaşımı ile personel seçimi. Yönetim ve Ekonomi Araştrmalan Dergisi. 14(2), 185-199.

Alford, B. D. (2004). Two applications involving the analytic hierarchy process (Doctoral dissertation).

Alnıpak, S. ve Yorulmaz, M. (2019). Tersane yöneticilerinin bakış açısından bütünleştirilmiş AHS-TOPSIS ve AHS-MOORA yöntemleri ile tersane kuruluş yeri seçimi: Akdeniz bölgesi örneği. Beykoz Akademi Dergisi, 7(2), 106-125.

Armstrong, M. (2004). Strategic human resource management. Kogan Page, London.

Baležentis, A., Baležentis, T. ve Brauers, W. K. (2012). Personnel selection based on computing with words and fuzzy MULTIMOORA. Expert Systems with applications, 39(9), 7961-7967.

Benli, A. ve Şahin, L. (2004). İnsan kaynakları yönetiminde işgören bulma ve seçme: Çınar hotel uygulaması. Bilgi Sosyal Bilimler Dergisi, 8, 113-124.

Brauers, W. K. M., ve Zavadskas, E. K. (2012). Robustness of MULTIMOORA: A method for multi-objective optimization. Informatica, 23(1), 1-25.

Brauers, W. K. ve Zavadskas, E. K. (2006). The MOORA method and its application to privatization in a transition economy. Control and cybernetics, 35, 445-469.

Brauers, W. K. M. ve Zavadskas, E. K., (2009). Robustness of the multiobjective MOORA method with a test for the facilities sector. Technological and Economic Development of Economy: Baltic Journal on Sustainability, 15(2), 352-375

Buğdayc1, A. (1997). Cv'ye sıkı takip. Capital Dergisi, 4. 168-169

Castilla, E. J. (2008). Gender, race, and meritocracy in organizational careers. American Journal of Sociology, 113(6), 1479-1526. 
Chakraborty, S. (2011). Applications of the MOORA method for decision making in manufacturing environment. The International Journal of Advanced Manufacturing Technology, 54(9-12), 1155-1166.

Cook, M. (2009). Personnel selection: Adding value through people-A changing picture. John Wiley E Sons.

Çelikbilek, Y. (2018). Personel seçimi için bütünleşik gri AHP-MOORA yaklaşımının kullanılması: sağlık sektöründe yönetici seçimi üzerine bir uygulama. Alphanumeric Journal, 6(1), 69-82.

El-Santawy, M.F. ve Ahmed, A.N. (2013). Personnel training selection problem based on SDV-MOORA. Life Science Journal-Acta Zhengzhou University Overseas Edition, 10(1), 1086-1088.

Ertürk, M. (2011). İnsan kaynakları yönetimi. Beta Basım Yayım Dă̆ıtım.

Gadakh, V. S. (2011). Application of MOORA method for parametric optimization of milling process. International Journal of Applied Engineering Research, 1(4), 743.

Güngör, Z., Serhadlıoğlu, G., ve Kesen, S. E. (2009). A fuzzy AHP approach to personnel selection problem. Applied Soft Computing, 9(2), 641-646.

Herişçakar, E. (1999). Gemi ana makine seçiminde çok kriterli karar verme yöntemleri ahp ve smart uygulaması. Gemi inşaatı ve deniz teknolojisi teknik kongresi, 99, 240256.

Kalibatas, D. ve Turskis Z., (2008), Multicriteria evaluation of inner climate by using moora method. Information Technology and Control,37, Vilnius Gediminas Tech. University Lthuania.

Kaynak, T., Adal, Z., Ataay, İ., Uyargil, C., Sadullah, Ö., Acar, A. C., Özçelik, O., Dündar, G. ve Uluhan, R. (2015). İnsan kaynakları yönetimi. Yedinci Baskı. İstanbul: Dönence Basim ve Yaym Hizmetleri.

Lootsma, F. A. (1999). Multicriteria decision analysis via ratio and difference judgement, Springer, London.

Oral, E. (2018). İnsan kaynakları uygulamalarının tükenmişlik sendromu üzerindeki etkisinde örgüt ikliminin düzenleyici rolüne yönelik bir araştırma. İstanbul Üniversitesi Sosyal Bilimler Enstitüsü Doktora Tezi.

Önay, O. (2014). MOORA. Yıldırım, F.B. ve Önder, E. (Ed.). Operasyonel, yönetsel ve stratejik problemlerin çözümünde çok kriterli karar verme yöntemleri. Dora yayinları. Bursa.

Özbek, A. (2015). Akademik birim yöneticilerinin MOORA yöntemiyle seçilmesi: Kırıkkale üzerine bir uygulama. Erciyes Üniversitesi Sosyal Bilimler Enstitüsü Dergisi, 1(38), 1-18. 
Paksoy, T., ve Atak, M. (2003). Etkileşimli bulanık çok amaçlı doğrusal programlama ile bütünleşik üretim planlama: hidrolik pompa imalaţ̧ısı firma örnek olayı. Gazi Üniversitesi, Fen Bilimleri Enstitïsü Dergisi, 457-466.

Palmer, M., ve Winters, K. (1993). İnsan kaynakları, Çev. Doğan Şahiner, Rota Yayınları, İstanbul.

Saaty, T. L. (1982). Decision making for leaders. Life time learning publications. Inc., Belmont, Calif.

Saaty, T. L. (1990). How to make a decision: the analytic hierarchy process. European Journal of Operations Research, 48(3), 9-26.

Saaty, T. L. (2002). Decision Making with the Analytic Hierarchy Process. Scientia Iranica, 9(3), 215-229.

Saaty, T.L. (1980). The analytic hierarchy process, McGraw-Hill, New York.

Taylor, F. A., Ketcham, A. F. ve Hoffman, D. (1998). Personnel evaluation with AHP. Management Decision.

Tepe, S. ve Görener, A. (2014). Analitik hiyerarşi süreci ve moora yöntemlerinin personel seçiminde uygulanması. İstanbul Ticaret Üniversitesi Fen Bilimleri Dergisi, 13(25), 1-14.

Timor, M. (2011). Analitik hiyerarşi prosesi. Türkmen Kitabevi.

Torrington, D. (1989). Personnel management. HRM in Action.

Tortop, N., Aykaç, B., Yayman, H. ve Özer, A. (2007). İnsan kaynakları yönetimi, Ankara: Nobel Yaym Dağttım.

Triantaphyllou, E. (2000). Multi-criteria decision making methods. In multi-criteria decision making methods: A comparative study (pp. 5-21). Springer, Boston, MA.

Urfahığlu, F., ve Genç, T. (2013). Çok kriterli karar verme teknikleri ile Türkiye'nin ekonomik performansını Avrupa birliği üye ülkeleri ile karşılaştırılması. Marmara University Journal of Economic \& Administrative Sciences, 35(2)

Ylldırım, B. F. ve Önay, O. (2013), Bulut teknolojisi firmalarını bulanık ahp-moora yöntemi kullanılarak sıralanması. Yönetim Dergisi, 75, 59-81.

\section{Kaynakça Bilgisi / Citation Information}

Acer, A. ve İnci, H. (2020). Personel seçimi sürecinin ahp tabanlı MOORA yöntemi ile değerlendirilmesi:Liman saha operasyon elemanı seçimi üzerine bir uygulama. OPUS-Uluslararası Toplum Araştırmaları Dergisi, 16(Özel Say1), 3689-3713. DOI: 10.26466/opus.716542 